Article

\title{
Research on the Damage Evolution Process of Steel Wire with Pre-Corroded Defects in Cable-Stayed Bridges
}

\author{
Ying Wang * and Yuqian Zheng \\ Jiangsu Key Laboratory of Engineering Mechanics, Southeast University, Nanjing 211189, China \\ * Correspondence: civil_wangying@seu.edu.cn; Tel.: +86-135-8404-8088
}

Received: 6 July 2019; Accepted: 31 July 2019; Published: 1 August 2019

\begin{abstract}
A numerical simulation method is presented in this paper to study the damage evolution and failure process of high-strength steel wires with pre-corrosion defects in cable-stayed bridges under fatigue loads. This method was based on the mechanism of crack nucleation accelerated by corrosion pits, in which cellular automata (CA) and finite element (FE) simulation methods were used. First, based on the continuum damage mechanics (CDM) theory, a fatigue damage model suitable for steel wire with pre-corroded defects was established to describe the evolution process of the microscopic damage of steel wires, and a user-defined material subroutine (UMAT) was written using formula translator (FORTRAN) language. Then, in MATLAB, the shape and position of random pitting defects on the steel wire surface were generated using 3D CA technology. Afterwards, a pitting defect model was successively inputted into AutoCAD, Rhino and ABAQUS software to obtain the FE model of steel wire with initial pitting defects or initial damage. Finally, the life-and-death element method and the UMAT program were used to simulate the fatigue damage evolution process of the steel wire with initial defects in ABAQUS software, and the fatigue life of the steel wire was obtained. The results show that the proposed strategy and algorithm can effectively describe the fatigue damage evolution process of the steel wire with initial pitting defects under the action of a fatigue load, and the simulated fatigue life is in good agreement with the experimental results. The obtained stress-life (S-N) curves of the steel wire with different corrosion degrees show that the influence of pit corrosion on fatigue life is much greater than that of the mass loss caused by corrosion. By comparing the irregular pit model with regular pit models, it can be found that the irregular shape angle is the main reason for the smaller fatigue life and the larger stress concentration in the irregular pit model than in the regular pit model.
\end{abstract}

Keywords: steel wire; pre-corrosion fatigue; cellular automata technology; damage evolution; life prediction

\section{Introduction}

A cable-stayed bridge is a cable support system consisting of three basic components: cables, towers and a bridge deck. During the service period, the safety of the entire bridge is inextricably intertwined with the properties of the cable system [1,2]. Just within the last 30 years, there have been many accidents caused by the damage and breakage of cables worldwide [3-5]. The average life of these cables is no more than 20 years, and compared with the 100-year designed life of the whole bridge, the life of the cable seems too short.

The most commonly used material for bridge cables is hot-dip galvanized high-strength steel wire, which possesses good comprehensive mechanical properties: high strength, good plasticity and good toughness [6]. In addition, the undamaged steel wire possesses a strong ability to resist fatigue 
crack nucleation but a weak ability to resist fatigue crack propagation [7]. But it is well known that corrosion can significantly reduce the fatigue life of steel wires, mainly because corrosion damage greatly shortens the fatigue crack initiation life of the wire during the service period, thus reducing the service life and residual strength of the steel wire [8]. Therefore, an in-depth study of the influence of pre-corrosion damage on the fatigue behavior of steel wires plays an important role in developing the life-cycle design theory of bridge structures and ensuring bridge safety.

At present, numerous experiments have been conducted, removing the barrier for life investigations of corroded steel wire. For example, Nakamura and Suzumura [9] conducted fatigue tests on steel wires with various corrosion degrees. The results show that the fatigue strength of corroded steel wires decreases greatly compared with the undamaged steel wire. After that, Nakamura and Suzumura [10] also investigated the pitting effect on steel wire fatigue properties. In addition, Zheng et al. [11] investigated the mechanical properties and fracture characteristics of in situ bridge wires by tensile and fatigue tests. The tests show that the ultimate strain of corroded wires decreased with an increase in the degree of corrosion, the fatigue properties of wires degraded significantly at the early corrosion stage and the degradation rate slowed down with further development of corrosion. Chao et al. [12] conducted experimental research on the fatigue performance of corroded steel wires by using 3D profile measurements and then established an empirical formula for fatigue life calculation based on test results.

Based on those experimental researches, some numerical methods were proposed to predict the fatigue life of corroded steel wires. For instance, Ye et al. [13] based their work on the theory of critical distances to estimate the fatigue life of corroded bridge wires, in which the stress concentration factor is recommended to be estimation indicator of the residual life of wires. Turnbull et al. [14] established a finite element (FE) model of steel wire with a hemi-spherical or bullet-shaped corrosive pit, simulated the growth of corrosive pits by removing units step-by-step, and then analyzed the distribution of the stress and strain fields around the corrosive pits at different stages. In addition, several calculational models are developed to predict the crack growth life of corroded steel wire based on fracture mechanics or damage mechanics [15-17], providing reference for the service safety performance and fatigue life evaluation of high-strength steel wire. In order to simplify the corrosion process, most studies introduced above presuppose the shape of the corrosion pit and assume that the pit evolves at the same rate in all directions.

However, the actual morphology and distribution of corrosion pits are uncontrollable, and shapes of corrosion pits are various, such as the narrow-deep pit, the ellipsoid pit, the wide-shallow pit and so on [18]. Hence, those simplistic studies have a limitation to simulate the authentic condition of pitting corrosion, and thus the fatigue life of corroded steel wires cannot be predicted accurately. In general, a more realistic pitting model should include a large number of random parameters related to the aspects of material science, electrochemistry, and mechanics. In addition, the corrosion morphology should be presented comprehensively rather than by a single corrosion eigenvalue, such as the mass loss rate and the pit depth. Therefore, based on local rules of pit growth, a numerical simulation method is proposed in this paper to present the morphology of corrosion pits and predict the fatigue life of steel wires with a corrosion pit.

The method proposed is based on the reasonable analysis of the essential characteristics of corrosion defects, which makes up for the shortcomings of the existing simulation methods only for regular 2D surface defects or 3D volume defects. The method fully considers the influence of random irregular morphology and the size of the corrosion pit on the mechanical property of steel wires and well predicts the residual life of steel wires under the action of fatigue loads. Therefore, the method has important theoretical and practical significance on the fatigue behavior prediction and service safety assessment of typical bridge wires. 


\section{Method Proposed}

The numerical simulation method developed to predict the damage evolution of corroded high-strength bridge wires under constant amplitude cyclic loads is as shown in Figure 1. First, a suitable fatigue damage model is chosen to compile a user-defined material subroutine (UMAT). Second, the shape and location of the initial pitting defects on the surfaces of high-strength bridge wires are obtained by utilizing 3D CA technology in MATLAB software (R2015a (8.5.0.197613), The MathWorks, Inc., Natick, MA, US, 2015). Third, the data of the initial pitting defects obtained above are inputted into AutoCAD, Rhino and ABAQUS software in sequence so that an FE model of steel wire with initial pre-corroded defects is established. Finally, the process of fatigue damage evolution is simulated in the FE model by using UMAT to study the fatigue life of steel wires with pre-corroded defects. The whole process of the method is described clearly and in detail in the following subsections.

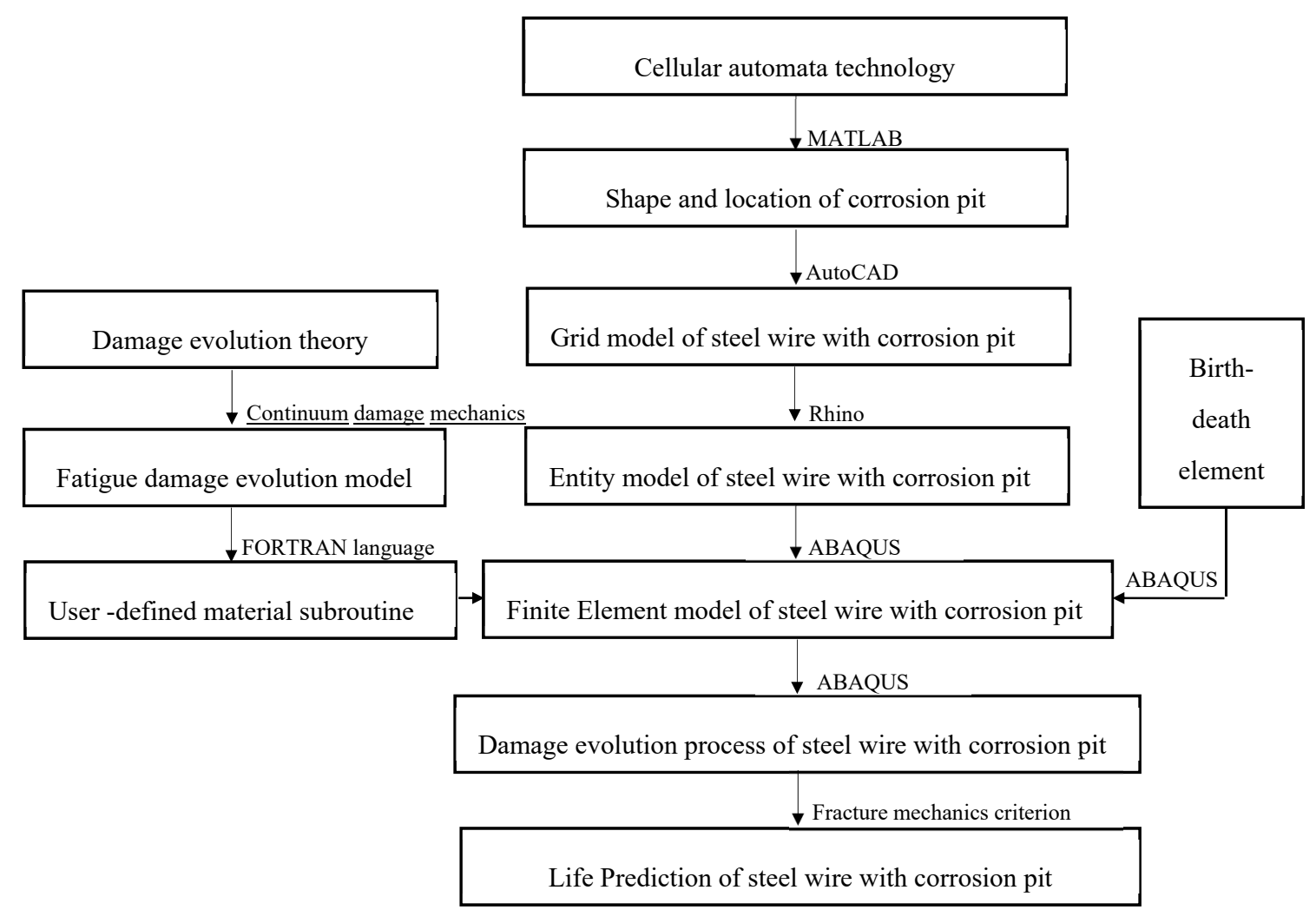

Figure 1. Flow chart of a numerical simulation of the damage evolution of high-strength steel wire under a pre-corrosion pit.

\subsection{Fatigue Damage Model of Bridge Wires Based on CDM}

The concept of continuum damage mechanics (CDM) was first presented by Kachanov [19] and has been the widely used in engineering applications, in which a damage variable $(D)$ is utilized to describe the degradation of material mechanical properties. The common form of the equation of fatigue damage evolution rate is written as:

$$
\frac{d D_{f}}{d N}=F_{f}\left(\sigma_{\max }, S, D_{f}, T, \ldots\right)
$$

where $D_{f}$ is the fatigue damage variable, $N$ is the cyclic number of loads, $\sigma_{\max }$ is the maximum stress, and $S$ is the stress range. 
In terms of stress, Equation (1) can be simplified as [18,19]:

$$
\frac{d D_{f}}{d N}=\left(1-D_{f}\right)^{-\mu}\left[\frac{S}{M_{0}}\right]^{B}
$$

where $\mu, B$ and $M_{0}$ are material parameters, which can be fitted by the stress-life (S-N) curve of steel wire from the fatigue tensile test.

Considering the initial condition ( $D_{f}=0$, when $N=0$ ), Equation (3) can be obtained by integrating Equation (2):

$$
D_{f}=1-\left\{1-(\mu+1)\left[\frac{S}{M_{0}}\right]^{B} N\right\}^{\frac{1}{\mu+1}}
$$

\subsection{Simulation of the Initial Damage by Using Cellular Automata (CA)}

The cellular automaton (CA) method was first proposed by Von Neumann in the 1940s. At present, CA has been used in many different fields to simulate the behavior of various systems, such as traffic statistics [20], bioinformatics [21] and material science [22]. For the metal corrosion problem, CA is also a powerful tool [23-25]. Compared with other the uncertainty methods, such as the neural network model [26], probabilistic analysis process model [27,28] and stochastic process model [29], the CA method has strong universality and stability in simulating the corrosion damage evolution process because it can integrate a lot of random parameters and present pit morphology comprehensively [30]. This article therefore adopts CA technology and the practical nature of the electrochemical reaction to simulate random pitting morphology and study the fatigue damage evolution process of corroded steel wire.

In the CA model, the metal/passive film/corrosive medium system is discretized into ordered cells in the three-dimensional cylindrical CA space. The cell space, the static component in the CA model, includes, based on the geometry of steel wire, the cylindrical coordinate system; according to the requirement of corrosion simulation accuracy, the steel wire and the external corrosion environment are divided into an array consisting of cells where the cell size is shown in Figure 2 and each cell is represented by its position coordinate $(i, j, k)$; the constant boundary condition is selected, that is, the outer cells of the boundary is endowed with a constant to describe a finite CA space; a three-dimensional cell space is established, as shown in Figure 2.

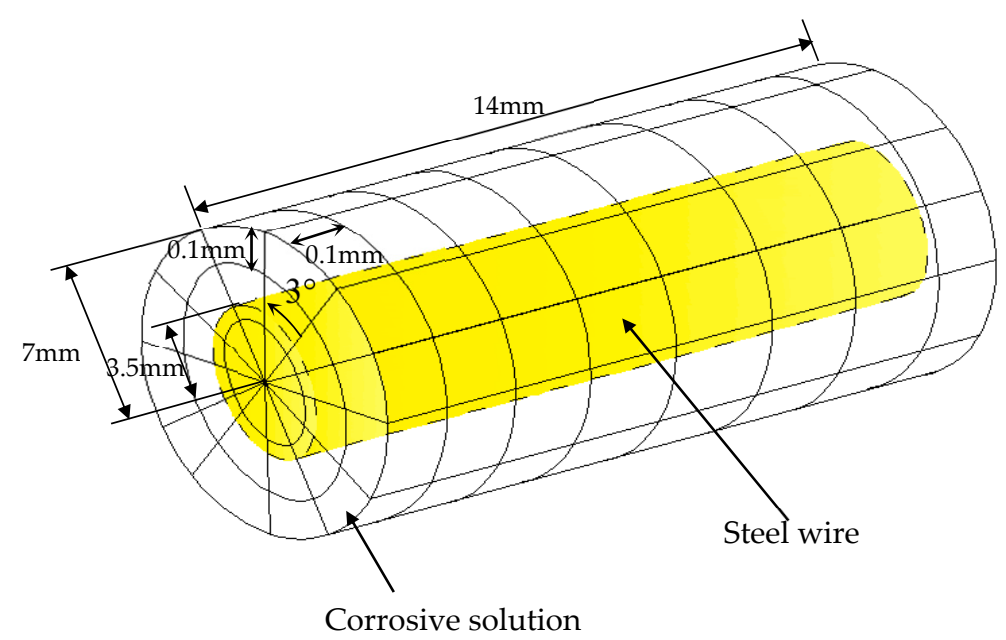

Figure 2. Schematic diagram of cellular automata (CA) model for the corrosion process of high-strength steel wire. 
The state of each cell $(i, j, k)$ in the cell space is determined by the cell characteristics at this position. In the CA model of metal corrosion, three cell types are mainly involved:

(1) Metal cell (M): the metal cell can be etched away by the corrosive cell, and its position remains unchanged throughout the simulation;

(2) Passive film cell (P): in the CA model, the passive film cell will cover the outermost metal cell initially. The position of the passive film cell is basically fixed, but the initial defect will randomly appear during the simulation, when the passive film cell at the position is converted into a metal cell;

(3) Corrosive cell (C): The corrosive cell is randomly distributed in solution and the concentration of the corrosive solution is set to 0.1. It can corrode the metal cell and move freely. In the cell space, the corrosive cell can randomly select to move along one direction of coordinate axis in each time step. That is to say, a 6-neighbor type is chosen.

The evolution rules of cells in the CA space are based on the basic metal corrosion process. Firstly, it is assumed that the corrosion system is a diffusion-controlled system, and the corrosion process only occurs at the interface of metal and electrolytes [31-33]. Thus, the general metal corrosion process can be described as: the passive film on the metal surface breaks; the exposed metal surface reacts electrochemically in a humid environment; the positive electrode gradually dissolves [30]. If the re-oxidation is not considered during the corrosion process, the basic reaction formula of the metal solution in an aqueous solution or a humid environment can be expressed as [32]:

$$
\mathrm{Me}+\mathrm{H}_{2} \mathrm{O} \rightarrow \mathrm{MeOH}_{\mathrm{aq}}+(1 / 2) \mathrm{H}_{2}
$$

where $\mathrm{MeOH}_{\mathrm{aq}}$ is the substance in the solution after the reaction, which has no influence on the subsequent corrosion process.

Therefore, in the CA model, the metal corrosion process can be divided into the following variation rules:

(1) Random diffusion of corrosive media in solution. In the CA model, within a time step, a cell C randomly selects one of its neighbors and is ready to move to the neighboring position. If the selected neighbor position is empty, the cell $C$ jumps to the neighbor cell.

(2) Metal dissolution. It is assumed that Equation (4) does not alter the acidity or alkalinity of the solution in the region. Therefore, in the cellular space, Equation (4) can be expressed as:

$$
\mathrm{M}+\mathrm{C} \rightarrow \mathrm{C}
$$

which indicates that when the metal dissolves, the current position of the cell $\mathrm{M}$ is occupied by the cell $\mathrm{C}$ of the neighboring position, and then the corresponding neighboring position becomes empty.

(3) Breakage of the passive film on the metal surface. In the CA model, if the selected neighbor is a cell $\mathrm{P}$ and the cell $\mathrm{C}$ is not located outside the metal space, the cell $\mathrm{P}$ will convert to a cell $\mathrm{M}$, i.e.,

$$
\mathrm{P} \rightarrow \mathrm{M}
$$

and then the cell $\mathrm{M}$ is corroded by the cell $\mathrm{C}$ as the Equation (5); while if the selected neighbor is a cell $\mathrm{P}$ but the cell $\mathrm{C}$ is located outside the metal space, the cell $\mathrm{C}$ remains its original position.

In addition, the following spatial correlation is introduced to limit the random diffusion process. Within a time step, a cell $C$ selects one of its neighbors. If the selected neighbor cell is empty or is occupied by a cell $\mathrm{M}$ but is chosen as a target position of another cell $\mathrm{C}$, the cell $\mathrm{C}$ remains its original position. Specifically, the steps of cell transformation are as shown in Figure 3. 


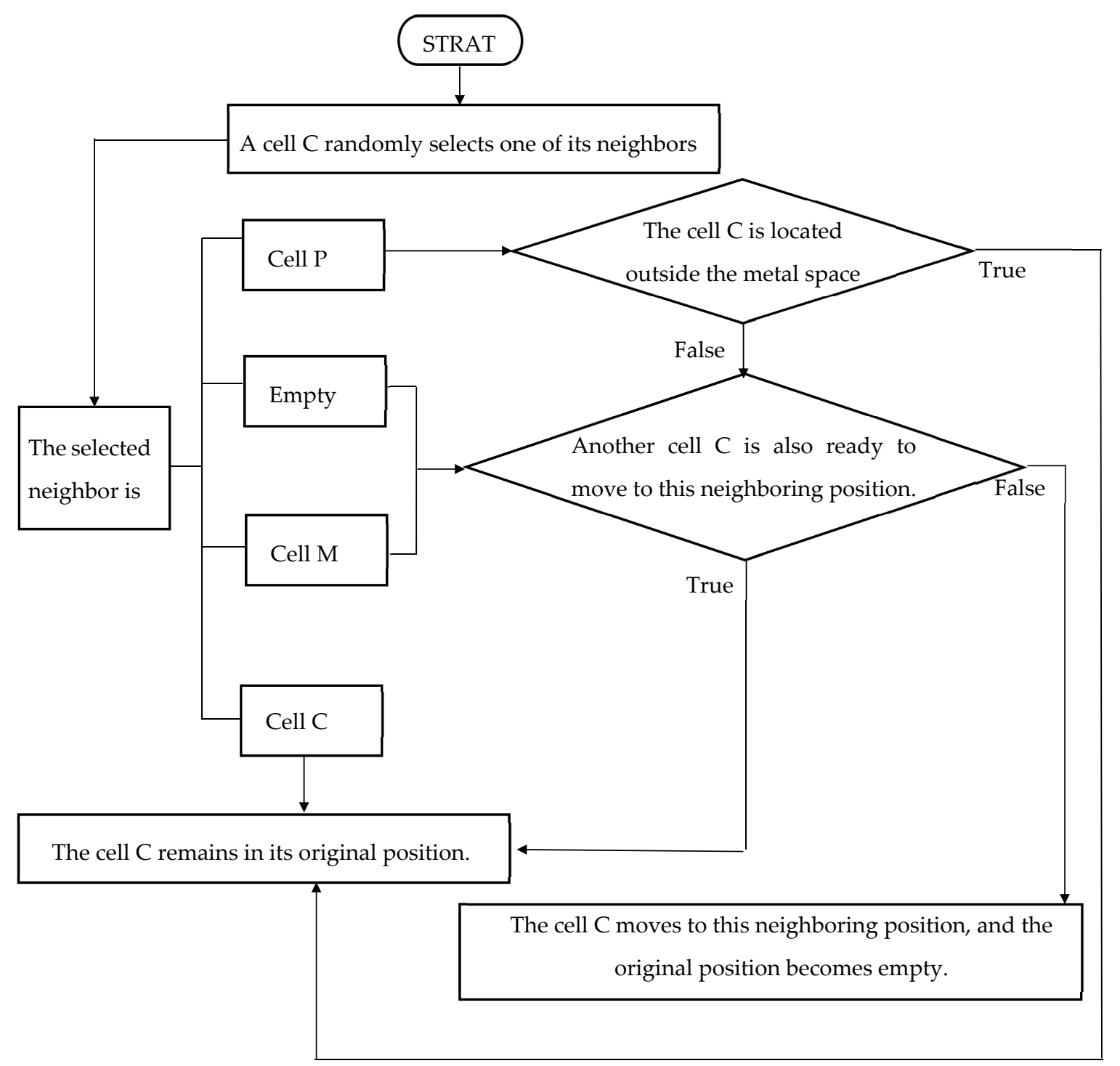

Figure 3. Cellular transformation rules.

To study the properties of corroded steel wire, a three-dimensional model of corroded wire must be established to further simulate the fatigue damage evolution of steel wire and predict its fatigue life. In order to establish the model, the data generated in the CA model are imported one by one into AutoCAD software (R2015a (8.5.0.197613), The MathWorks, Inc., Natick, MA, US, 2015), Rhino software (D.306.0.0, AutoCAD 2010 - Simplified Chinese Version 3, Autodesk, Inc., San Rafael, CA, US, 2010) and ABAQUS software (Abaqus/CAE 6.14-4, Dassault Systèmes, Providence, RI, US, 2015). The object of the whole process is to easily realize the visualization and substantialization of the corrosion pit generated by the CA method. Specifically, the grid model is generated directly by data transmission between MATLAB software and ABAQUS software. Then, the grid model is inputted into Rhino software to generate a surface model that is irregular but smooth. And a 3D solid model is generated in Rhino software directly by using the function of automatic solid generation. Finally, the 3D solid model is inputted into ABAQUS software to generate the FE model used for damage evolution simulation.

\subsection{Fatigue Damage Simulation Algorithm (UMAT)}

User-defined material mechanical behavior (UMAT) is a FORTRAN interface program provided by ABAQUS to users to customize material properties, and thus an undefined material modeled in ABAQUS software can be realized by UAMT. The ABAQUS software can call these material 
subroutines and analyze the structure by exchanging data with them. Therefore, in this paper, a UMAT is compiled to simulate the fatigue damage accumulation of steel wires in ABAQUS software according to Equation (3).

The algorithm of user-defined material subroutine (UMAT) based on the fatigue damage model in Section 2.1 is shown in Figure 4. Four state variables are utilized in the UMAT. STATEV(1) and STATEV(2) store the stress values calculated in the loading analysis and unloading analysis steps, respectively. The role of STATEV(3) is to store the current elastic modulus of the material in each analysis step. STATEV(4) is used to store the accumulated damage in each analysis step.

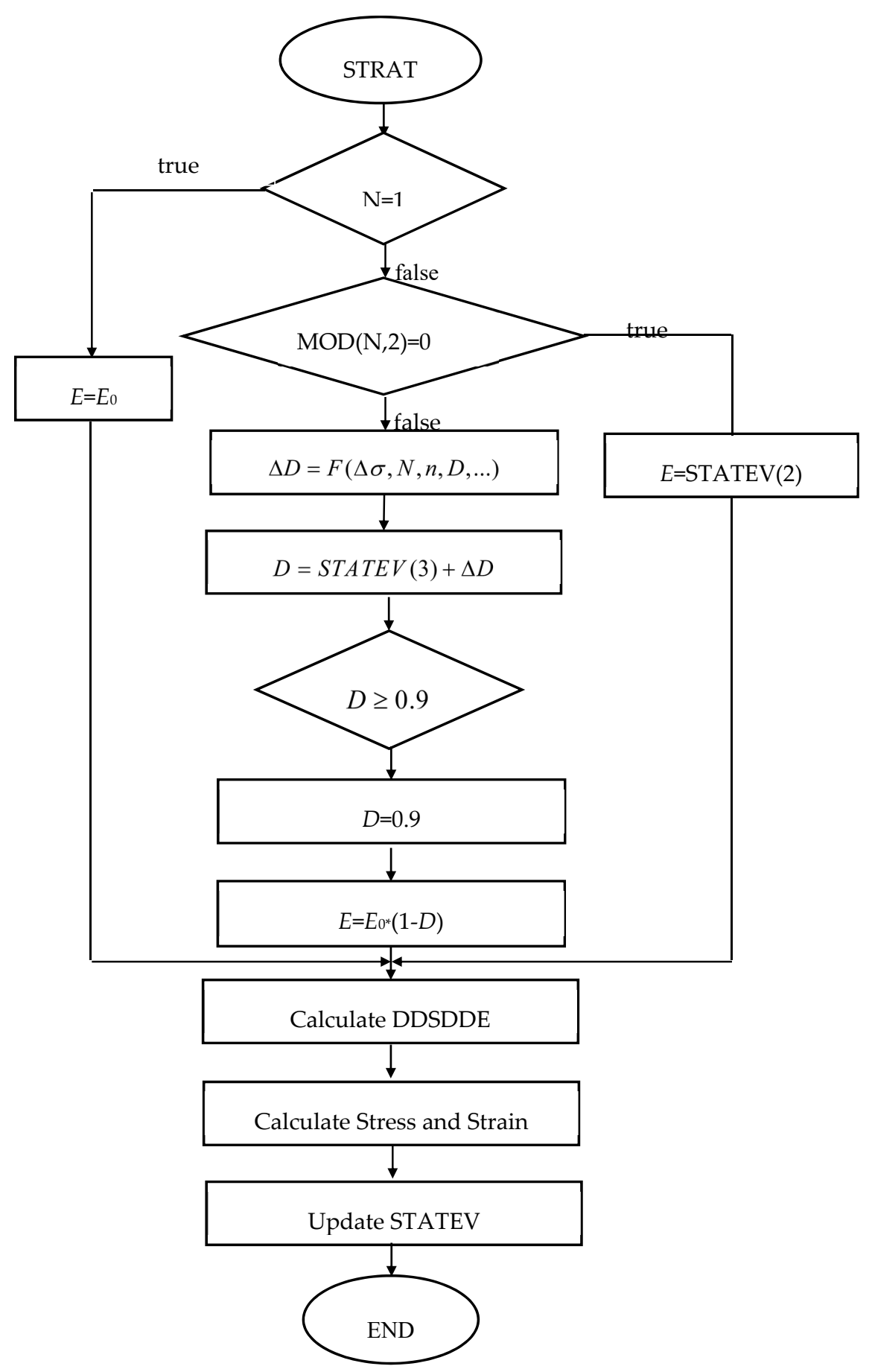

Figure 4. Flow chart of user-defined material subroutine (UMAT) algorithm. 
After UMAT is called, it will determine whether the current step inputted from ABAQUS software is the first step. If the step is the first step, which means that there is no damage in each element, then the current elastic modulus is the initial elastic modulus. If the step is not the first step but is an unloading step, then the current elastic modulus equals the elastic modulus of the above step. If the step is not the first step but is a loading step, the damage is calculated by using the fatigue damage model in Section 2.1. Additionally, the current elastic modulus is deducted from the accumulation of damage, i.e.,

$$
E=E_{0} \times(1-D)
$$

where, $E$ is the current elastic modulus, $E_{0}$ is the initial elastic modulus and $D$ is the accumulated damage variable. Before calculating the damage variable, it is necessary to calculate the stress difference between the previous loading and unloading step, that is, the stress range. Using the calculated stress range, the damage increment is calculated based on Equation (3). The damage increment refers to the damage produced after a cyclic load as follows:

$$
\Delta D_{f}=D_{f}(S, N-1)-D_{f}(S, N-2)
$$

where, $N$ is the number of the loading step, $\Delta D_{f}$ is the damage increment produced after the previous cyclic load, and $S$ is the stress difference between the previous loading and unloading step. The damage increment is then added into the damage variable that has been stored in the STATEV(4). The calculated damage variable refers to the accumulated damage before the current step.

Notably, the cycle block used in this paper represents certain times of loading, such as 5000 times, 10,000 times and 20,000 times, namely accuracy in this paper. It is well-grounded that the value of damage is invariable during each cycle block but accumulates and updates in the beginning of the next cycle block on the basis of the state variables. The relationship among the loading number, cyclic block, calculation accuracy and analysis step can be expressed as follows:

$$
\begin{gathered}
N_{c b}=\operatorname{INT}\left(\frac{N}{n}\right) \\
N_{c b}=\left(N_{a s}+1\right) / 2 \text { if } N_{a s} \text { is odd } \\
N_{c b}=N_{a s} / 2 \text { if } N_{a s} \text { is even }
\end{gathered}
$$

where, $N_{c b}$ is the number of cyclic blocks, $N$ is the total number of cyclic loads, $n$ is computational accuracy, $N_{a s}$ is the analysis step and INT( ) is the integral function.

\subsection{Verification of the Proposed Method}

To verify the developed UMAT, a median stress vs. number of cycles to failure $(S-N)$ curve chosen from [34] is expressed as:

$$
\lg N_{c}=23.480-6.649 \lg S
$$

which is obtained from fatigue experiments of 12 high-strength bridge wire samples under four different cycle tensile forces with a constant stress range.

According to Equation (3), $D_{f}\left(N_{c}\right)=1$, where $N_{c}$ is the fatigue life of a high-strength bridge wire, is chosen to fit the S-N curve to obtain the value of the model parameters. Therefore, by using the obtained parameters above, Equation (3) can be expressed as:

$$
\frac{d D_{f}}{d N}=\left(1-D_{f}\right)^{-1}\left[\frac{S}{3772.53}\right]^{6.649}
$$

Based on Equation (13), an FE model of a high-strength bridge wire without initial damage is developed in ABAQUS software using UMAT to predict the fatigue life of the bridge wire under stress 
ranges ranging from $335 \mathrm{MPa}$ to $670 \mathrm{MPa}$. Besides, the initial elastic modulus is 212,000 MPa and Poisson's ratio equals 0.3 .

The simulation results are shown in Figure 5 and are compared with the S-N curve given in [34]. These data show that the predicted results using UMAT agree well with the S-N curve, which means that the developed UMAT and fitted model parameters are reasonable and effective.

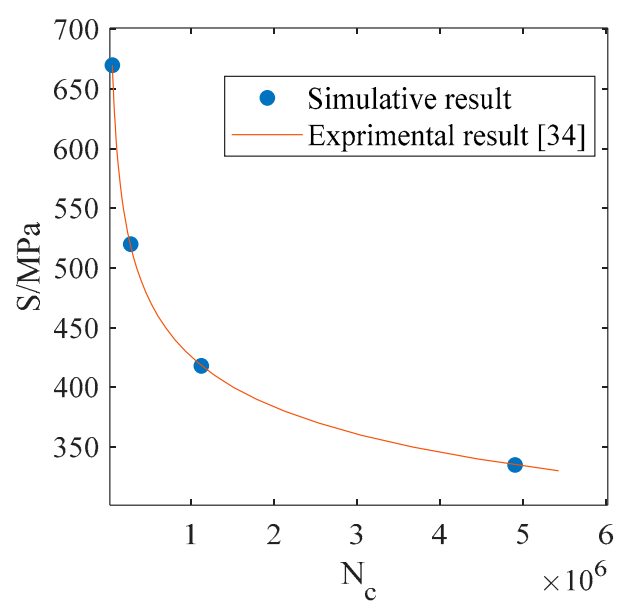

Figure 5. S-N curve of steel wire without the initial defect under uniaxial tensile fatigue loads.

In addition, since the main object of this paper is to simulate the fatigue damage evolution of corroded steel wires, verification against a structure with defects needs to be made. Based on Equation (13), an FE model of a high-strength bridge wire with a hemispherical pit is developed in ABAQUS software using UMAT to predict the fatigue life of the bridge wire under stress ranges ranging from $335 \mathrm{MPa}$ to $670 \mathrm{MPa}$. The radius of the hemispherical pit equals $1 \mathrm{~mm}$.

The simulation results are compared with the results that are calculated by a numerical model developed in [7]. According to [7], the equation for predicting the fatigue life $N_{c}$ of corroded steel wires can be deduced from the Paris law with an integral operation:

$$
N_{c}=\frac{1}{\operatorname{CS}^{m}} \int_{x_{0}}^{x_{c}}(Y \cdot \sqrt{\pi x})^{-m} d x
$$

where, $C$ and $m$ are undetermined parameters that equal $1.39 \times 10^{-12}$ and 3.3 respectively for steel wire with the diameter of $7 \mathrm{~mm}$ when the stress ratio $R$ is 0.5 according to [35]; $x$ is the crack length, $x_{0}$ is the initial crack length that equals $1 \mathrm{~mm}$ in this paper and $x_{c}$ is the critical crack length that is calculated by the fracture toughness that equals $65.7 \mathrm{MPa} \cdot \sqrt{m}[6] ; S$ is the stress ranges ranging from $360 \mathrm{MPa}$ to $670 \mathrm{MPa} ; Y$ is the crack shape factor. According to [35], $Y$ can be expressed as:

$$
Y=1.4835-2.9219\left(\frac{x}{D}\right)+5.9602\left(\frac{x}{D}\right)^{2}+1.6304\left(\frac{x}{D}\right)^{3}
$$

where $D$ is the diameter of steel wire and equals $7 \mathrm{~mm}$ in this paper.

The above two results are compared in Figure 6. The comparison shows that the UMAT written in this paper can achieve the expected goal and that the calculation results are also consistent well with the results calculated by the numerical model proposed in the literature $[7,35]$. 


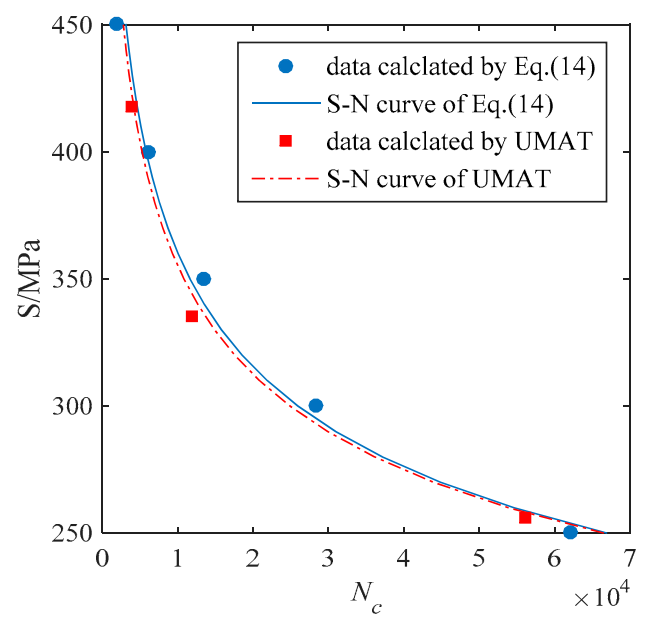

Figure 6. S-N curve of steel wire with a hemispherical pit under uniaxial tensile fatigue load.

\section{Examples}

Based on the above-proposed method, the damage evolution of high-strength steel wires with a pre-corroded defect can be simulated, in which the fatigue life of corroded steel wires can be acquired. To evaluate the corrosion degree of the steel wire, the mass loss rate is introduced and can be expressed as:

$$
\eta=\frac{m_{0}-m_{1}}{m_{0}} \times 100 \%=\frac{v_{0}-v_{1}}{v_{0}} \times 100 \%
$$

where $m_{0}$ and $v_{0}$ are the initial mass and volume of the high-strength steel wire, respectively; $m_{1}$ and $v_{1}$ are the mass and volume of the corroded wire after clearing, respectively.

After 1 day, 10 days, 30 days and 60 days of accelerated corrosion testing, the average mass loss rate of high-strength steel wire was $0.25 \%, 1.85 \%, 2.5 \%$ and $3.33 \%$, respectively [36]. Considering the dispersion of the corrosion pits in the tests, most of the related experiments have focused on only the fatigue performance of the steel wires with uniform corrosion. However, the location where the fracture occurs is often a pitting defect on the steel wire surface [12]. Therefore, to be consistent with the uniform corrosion degree in the literature [36], the model established in this paper only sets the upper surface of the middle part of the steel wire as the corrosion area, namely, the yellow part in Figure 7. The size of the initial defect that is set in CA space is $0.5 \mathrm{~mm} \times 0.5 \mathrm{~mm}$, as shown in Figure 7 . Then, CA technology is used to generate a steel wire model with a pre-corroded defect at each mass loss rate, as shown in Figure 8.

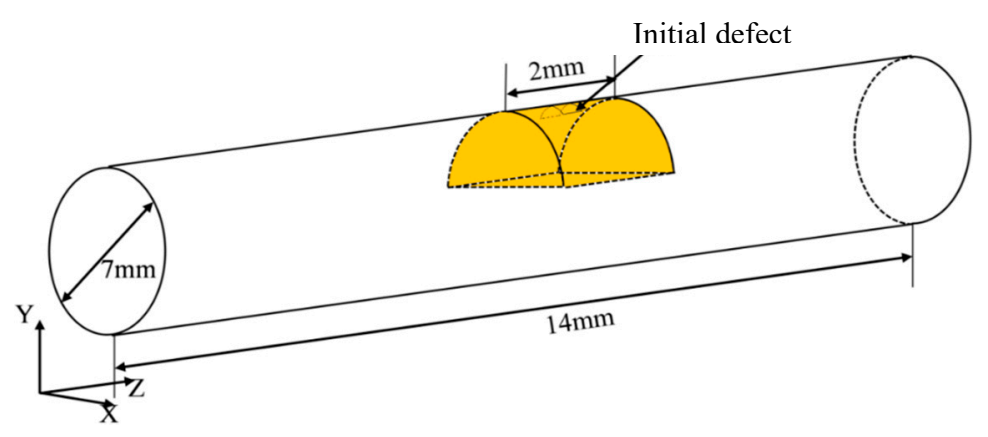

Figure 7. Pre-corroded steel wire model and its size. 


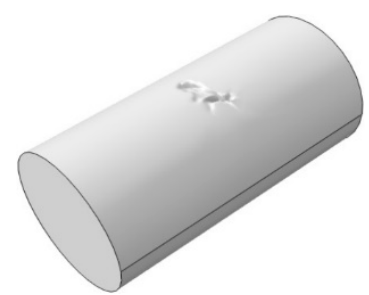

(a)

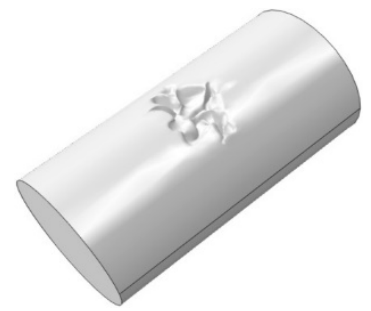

(c)

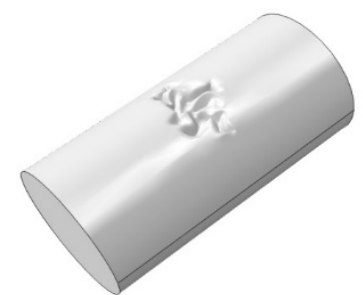

(b)

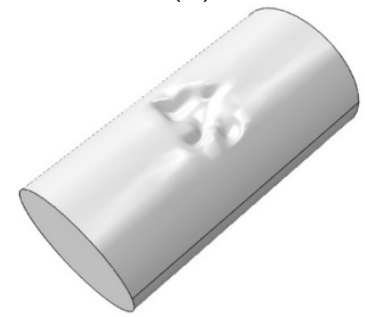

(d)

Figure 8. Model of steel wire with a pre-corroded defect at each mass loss rate: (a) $\eta=0.25 \%$; (b) $\eta=1.85 \%$; (c) $\eta=2.5 \%$; (d) $\eta=3.33 \%$.

To study the fatigue performance of corroded steel wires, fatigue loads with a stress ratio of 0.5 and stress ranges of $335 \mathrm{MPa}, 418 \mathrm{MPa}$, and $520 \mathrm{MPa}$ are applied to the steel wires. The material properties are the same as that of the undamaged steel wire model in Section 2.4.

\subsection{Fatigue Life of Pre-Corroded Steel Wire}

After a fatigue crack in a high-strength steel wire is formed, it will continue to propagate under alternating loads. When the stress intensity factor $K_{I}$ of the crack reaches the fracture toughness $K_{I C}$, a fracture occurs, which can be expressed as Equation (17) given in [37]:

$$
K_{I}=Y_{\sigma} \sqrt{\pi x}<K_{I C}
$$

where $\sigma$ is the stress in the specimen; $Y$ is the crack shape factor, and for the hemi-elliptic surface crack under tension on the cylinder, $Y$ can be expressed as [25]:

$$
Y=\frac{\frac{1.84}{\pi}\left[\tan \left(\frac{\pi x}{2 D}\right) / \frac{\pi x}{2 D}\right]^{\frac{1}{2}}}{\cos \left(\frac{\pi x}{2 D}\right)} \times\left[0.752+2.02 \frac{x}{D}+0.37\left(1-\sin \left(\frac{\pi x}{2 D}\right)^{3}\right)\right]
$$

where $x$ is the depth of the pit and $D$ is the diameter of the wire. In this paper, in order to unify the damage assessment system, the stress intensity factor is used to quantify the overall damage degree of high strength steel wire. Therefore, the irregular corrosion pit is equivalent to a hemi-elliptic surface crack and does not make too much distinction between the corrosion pit and the crack. Based on the above assumption, the stress intensity factor can be calculated easily by using Equation (17) and Equation (18). According to [6], the fracture toughness of a high-strength steel wire with a diameter of $7 \mathrm{~mm}$ is $65.7 \mathrm{MPa} \cdot \sqrt{m}$.

Based on the simulation strategy proposed, the fatigue life of pre-corroded steel wires with different mass loss rates is obtained, as shown in Table 1. Notably, as mentioned above, the accuracy in Table 1 is the ratio of the number of real load cycle to the cycle block. In Table 1, compared with the test results, the fatigue life of the pre-corroded steel wire obtained by this strategy is generally conservative. Specifically, when the corrosion degree and the stress range are large, the gap between these two is wide. This effect is mainly caused by two reasons: (1) the experimental data given in [36] originate from a uniform corrosion test. The number and distribution of corrosion pits in this experiment are random, which is not totally consistent with the model established in Figure 9, especially when the corrosion 
degree is large. (2) The initial pitting morphology generated by CA is also random. The randomness of the simulation and test results leads to the gap between them, but the results of both are on the same order of magnitude. Furthermore, the average deviation is approximately $20.24 \%$, which shows the reliability and practicability of this method in predicting the fatigue life of pre-corroded steel wire.

Table 1. Life of pre-corroded steel wire.

\begin{tabular}{ccccccccc}
\hline$\eta / \%$ & $\begin{array}{c}\mathbf{S} \\
\text { /MPa }\end{array}$ & $\mathbf{n}$ & Step & $x / \mathbf{m m}$ & $\begin{array}{c}\boldsymbol{K}_{\mathbf{I}} \\
/ \mathbf{M P a} \cdot \sqrt{\mathbf{m}}\end{array}$ & $\mathbf{N c}$ & $\begin{array}{c}\text { Test Results of } \\
\text { Fatigue Life [23] }\end{array}$ & Error \\
\hline \multirow{3}{*}{$0.25 \%$} & 335 & 100,000 & 93 & 2.15662 & 64.9195 & $4,700,000$ & $4,220,614$ & $11.36 \%$ \\
& 418 & 10,000 & 195 & 1.75383 & 64.9673 & 980,000 & $1,040,139$ & $6.14 \%$ \\
& 520 & 10,000 & 45 & 1.34251 & 63.0924 & 230,000 & 240,066 & $4.19 \%$ \\
\hline \multirow{3}{*}{$1.85 \%$} & 335 & 50,000 & 99 & 2.15101 & 64.7262 & $2,500,000$ & $2,498,912$ & $0.04 \%$ \\
& 418 & 10,000 & 95 & 1.75383 & 64.9678 & 480,000 & 641,358 & $25.16 \%$ \\
& 520 & 2,000 & 109 & 1.9253 & 65.1381 & 110,000 & 173,800 & $36.71 \%$ \\
\hline \multirow{3}{*}{$2.5 \%$} & 335 & 20,000 & 185 & 2.17891 & 65.6922 & $1,860,000$ & $1,304,947$ & $42.53 \%$ \\
& 418 & 10,000 & 73 & 1.70954 & 63.3443 & 370,000 & 523,005 & $29.25 \%$ \\
& 520 & 1000 & 171 & 1.39672 & 65.3108 & 86,000 & 119,363 & $27.95 \%$ \\
\hline \multirow{3}{*}{$3.33 \%$} & 335 & 10,000 & 189 & 2.15813 & 64.9717 & 950,000 & 821,534 & $15.64 \%$ \\
& 418 & 10,000 & 73 & 1.71762 & 63.6386 & 370,000 & 398,024 & $7.04 \%$ \\
& 520 & 2000 & 61 & 1.40164 & 65.5137 & 61,000 & 96,681 & $36.90 \%$ \\
\hline
\end{tabular}

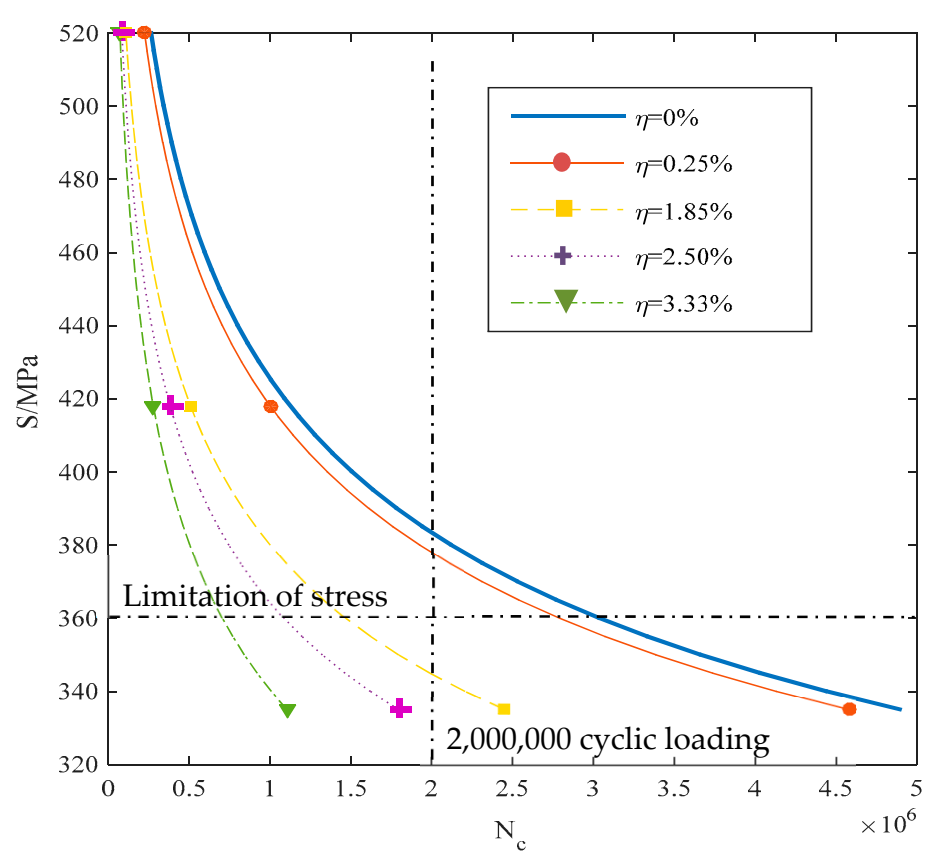

Figure 9. S-N curves of steel wires with different degrees of pre-corrosion.

Figure 9 shows the S-N curves of steel wires with different degrees of pre-corrosion. From Figure 9 , the fatigue performance of steel wires decreases with increasing corrosion degree, which is consistent with other conclusions in the literature $[7,35,38]$. Hence, it could be found that the influence of pitting corrosion on the fatigue life is far greater than the mass loss. In addition, according to the Chinese standard [39], when stress range equals $360 \mathrm{MPa}$, it is required that the fatigue life of hot-dip galvanized high-strength steel wire for bridge cables is more than 2,000,000 cycles. Hence, from Figure 9, the corroded steel wire with a mass loss rate of $0.25 \%$ still satisfies the requirement but if the mass loss rate is equal or greater than $1.85 \%$, the fatigue life of steel wire reduces to less than 2,000,000 cycles, which no longer meets the requirement and cannot be used. 


\subsection{The Process of Damage Evolution}

To study the influence of the pitting morphology on the damage evolution, a pre-corroded steel wire with a mass loss rate of $0.25 \%$ under a stress range of $418 \mathrm{MPa}$ was selected to present the damage evolution process.

Figure 10 shows the stress and damage distribution of the steel wire specimen at the 195th step, when it is about to fracture. Figure 10a shows that the maximum stress appears at the bottom of the pit, and the high stress zone presents a zonal distribution perpendicular to the tension direction. The minimum stress appears at the edge of the pit, and the low-stress zone is distributed along the axis. Figure 10b shows that fatigue failure mainly occurs in the high-stress zone and presents a zonal distribution perpendicular to the tension direction.

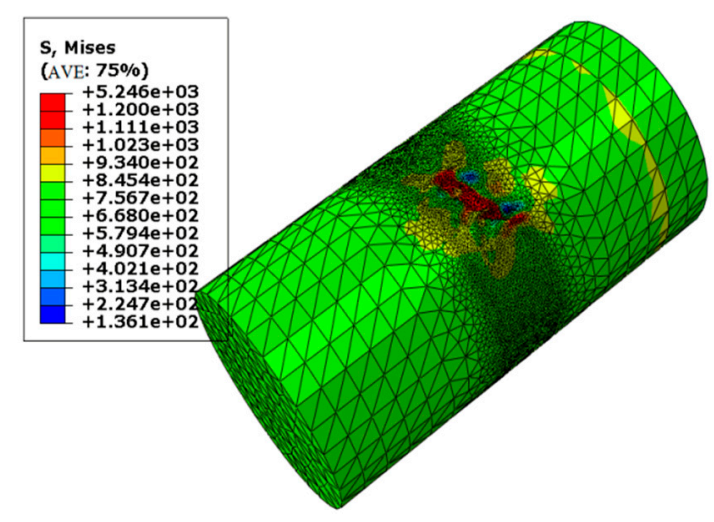

(a)

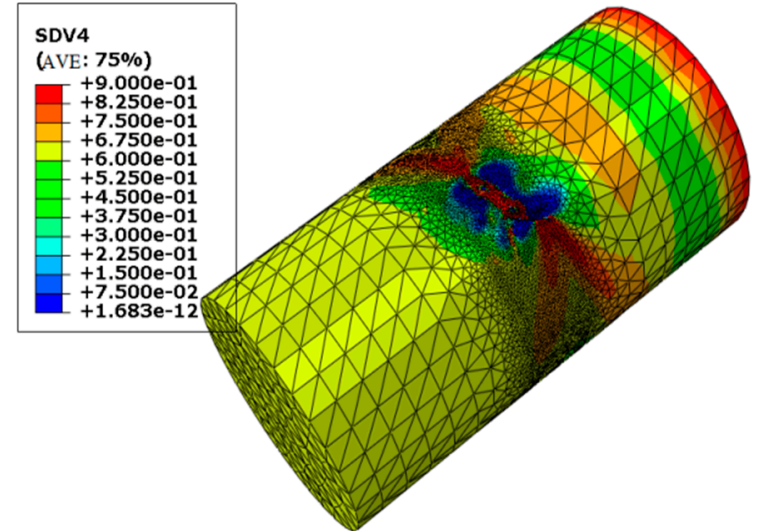

(b)

Figure 10. Stress and damage contours of corroded steel wire (step = 195): (a) Stress distribution; (b) Damage distribution.

Figure 11 shows the damage evolution process and stress distribution on a cross section of the model $(z=7 \mathrm{~mm})$. The stress concentration occurs in the middle of the pit, where the damage begins to accumulate gradually. As the number of cyclic loads continues to increase, damage accumulates and penetrates into the inner zone of the steel wire far from the pit. In addition, the stress distribution in the steel wire also changes with the cyclic loading process. Due to the stress concentration, the elastic modulus of the material near the pit will gradually decline with cyclic loading, so that the deformation energy of the material can be changed locally and its stiffness will decrease compared with other areas. However, under these circumstances, the damaged material still has the ability to transfer stress and is still continuous with the surrounding material, which makes the adjacent material bear a higher stress.

Figure 12 presents the time-varying curves of the stress intensity factor and the size of defect. As shown in Figure 12, with the increase of the loading step, the defect size gradually increases, the damage gradually accumulates, and the rate of damage evolution gradually increases. When the step equals 195, the defect size is $1.75383 \mathrm{~mm}$, the stress intensity factor is $64.967 \mathrm{MPa} \cdot \sqrt{\mathrm{m}}$, which is close to the fracture toughness, and the steel wire could begin to fracture. 


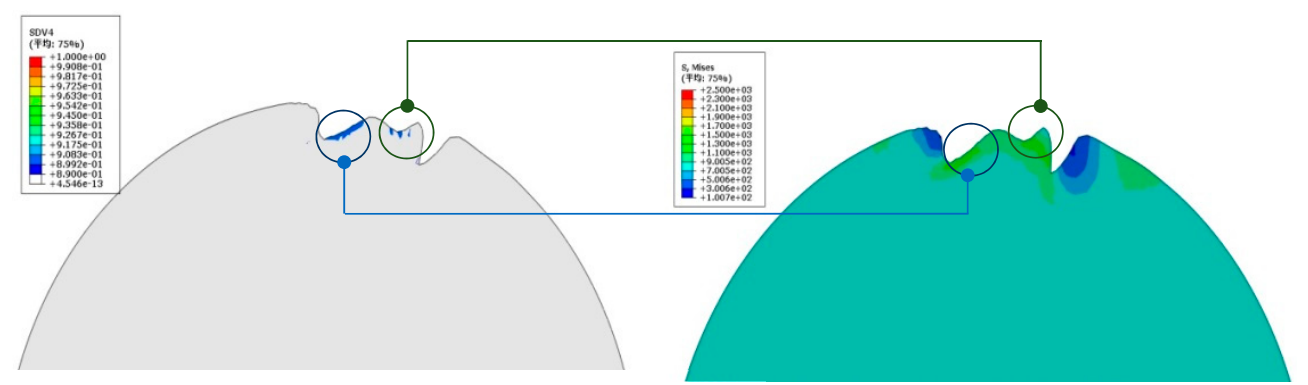

(a)
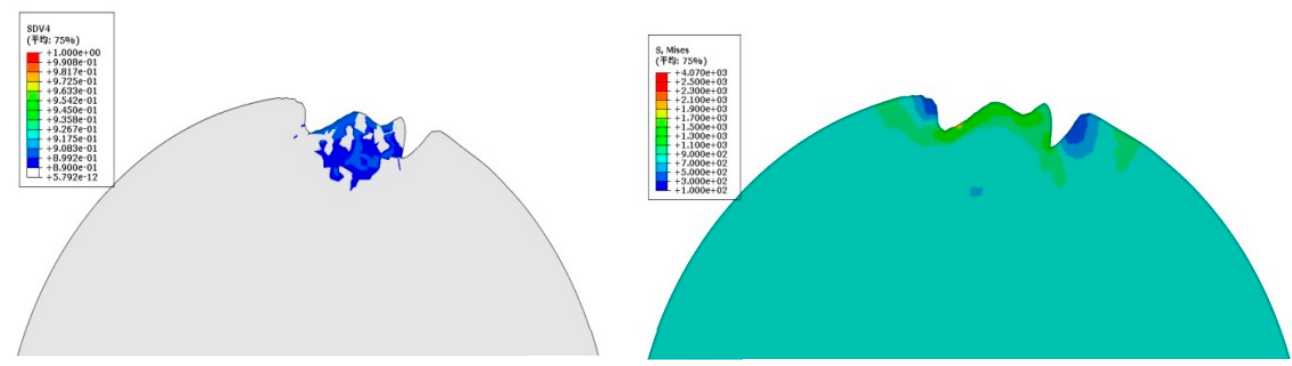

(b)
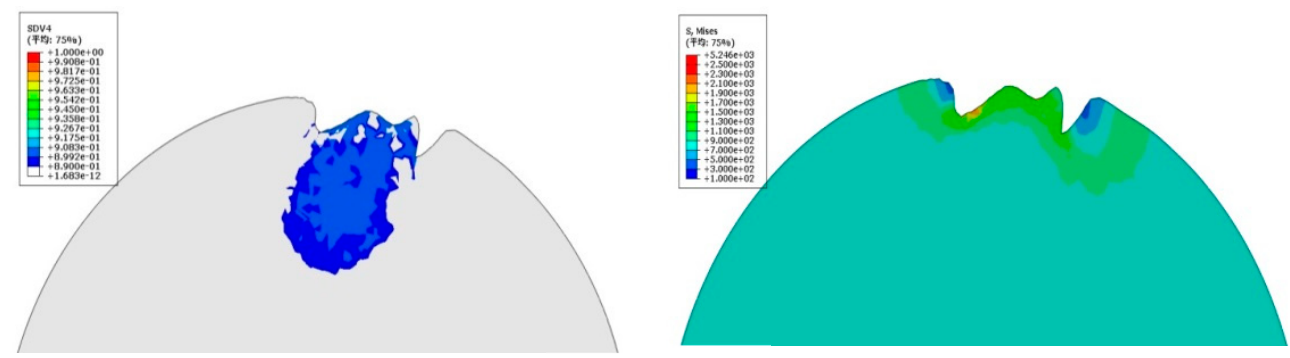

(c)

Figure 11. Damage evolution process and stress distribution of pre-corroded steel wire on a cross section. (a) step $=51 ;(\mathbf{b})$ step $=151 ;(\mathbf{c})$ step $=195$.

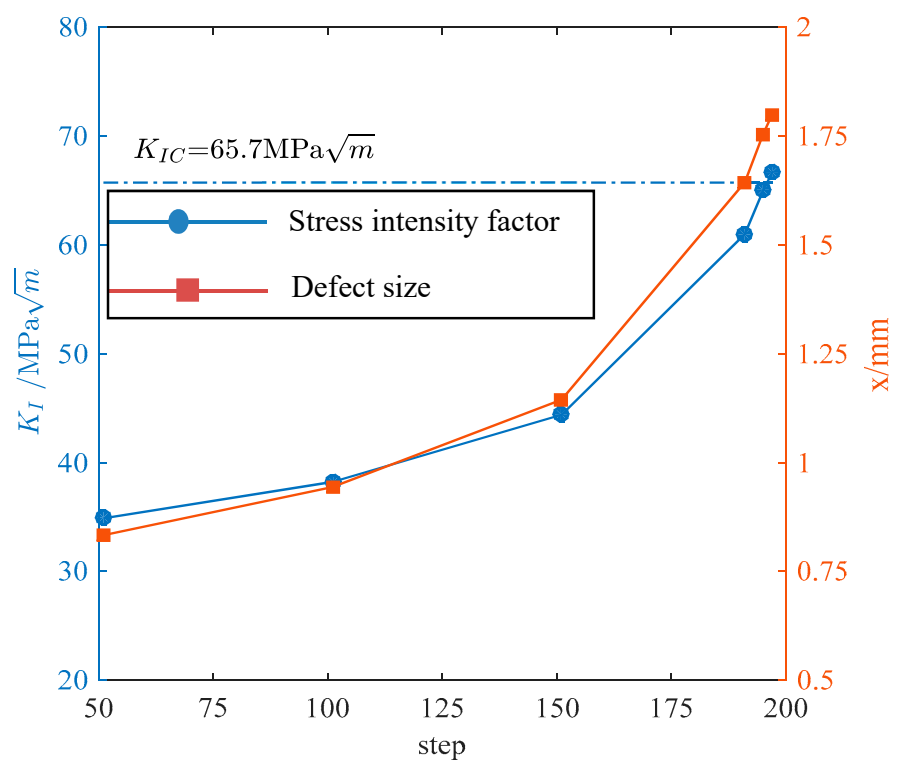

Figure 12. Time-varying curves of the stress intensity factor and defect size in steel wire.

\subsection{Influence of the Initial Pitting Morphology on the Fatigue Life}

To verify the accuracy and advantage of the proposed numerical simulation method, the fatigue life of the corresponding steel wires with a regular pit is calculated and compared with the above 
results. First, the pit shape factor $\lambda$ proposed by Harlow et al. [40] is used to determine the morphology of the regular pit, which can be defined as:

$$
\lambda=c / a
$$

where $c$ and $a$ represent the width and depth of the corrosion pit, respectively.

Then, hemi-ellipsoidal pit models with shape factors of $0.25,0.5,1.0,1.5$ and 2.0 are established. The mass loss rate of all hemi-ellipsoidal pits is $0.25 \%$, which is consistent with the random pit generated by CA technology in Figure 8a. The example of established models of the pre-corroded steel wire with a regular pit is shown in Figure 13. Finally, the UMAT developed in Section 2.3 is used to calculate the fatigue life of each model, and the results are shown in Table 2.

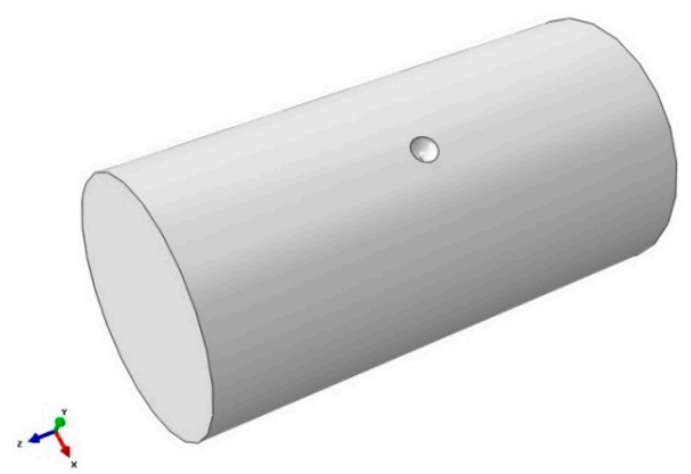

Figure 13. Pre-corroded steel wire model with regular a corrosion pit $(\lambda=1.0)$.

Table 2. Life of pre-corroded steel wire with a regular corrosion pit ( $\eta=0.25 \%)$.

\begin{tabular}{ccccc}
\hline S/MPa & $n$ & $\lambda$ & $x / \mathbf{m m}$ & $N_{c}$ \\
\hline \multirow{3}{*}{335} & \multirow{2}{*}{100,000} & 0.25 & 0.90246 & $4,900,000$ \\
& & 0.5 & 0.5685 & $5,000,000$ \\
& & 1.0 & 0.358 & $5,100,000$ \\
& & 2.0 & 0.27331 & $5,200,000$ \\
& & 0.25 & 0.90246 & $5,400,000$ \\
\hline \multirow{3}{*}{418} & \multirow{3}{*}{10,000} & 0.5 & 0.5685 & $1,060,000$ \\
& & 1.0 & 0.358 & $1,090,000$ \\
& & 1.5 & 0.27331 & $1,100,000$ \\
& & 2.0 & 0.2256 & $1,200,000$ \\
\hline \multirow{3}{*}{520} & \multirow{3}{*}{5000} & 0.25 & 0.90246 & 235,000 \\
& & 0.5 & 0.5685 & 245,000 \\
& & 1.0 & 0.358 & 250,000 \\
& & 2.0 & 0.27331 & 255,000 \\
& & 0.2256 & 280,000 \\
\hline
\end{tabular}

From Table 2, at the same stress range, even if the mass loss rate is the same, the fatigue life of the pre-corroded steel wire increases gradually with an increase in the pit shape factor, that is, a reduction in the pit depth. In addition, compared with wide-shallow pits, narrow and deep pits have a greater impact on the fatigue performance of steel wires, which is consistent with the conclusions given in $[17,41]$. From a qualitative point of view, this behavior is because the stress concentration of hemi-ellipsoidal pit gradually decreases with increasing of $\lambda$, which reduces the fatigue damage accumulation rate and eventually leads to an increase in the fatigue life of the corroded steel wire.

Figure 14 shows the S-N curves of the steel wires with a hemi-ellipsoidal pit. Compared with the corresponding S-N curve of the steel wire with a random corrosion pit, the fatigue life of the steel wire with a random pit is less than that of the other two hemi-ellipsoidal pit models, even though the 
maximum depth of the random pit is less than that of the hemi-ellipsoidal pit with a shape factor of 0.25 . Based on the simulative results of these models, the reason why the random pit model has a small depth but a low fatigue life is investigated. Figure 15a,b are stress contours of random pit model and the hemi-ellipsoidal pit model. From the point of view of stress, the maximum stress of the random pit model is 1.162 times that of the hemi-ellipsoid pit model with shape factor of 0.25 . The excessive stress concentration of the random pit model is caused by the irregular sharp angle in the pit, such as point $\mathrm{A}$ in Figure 15a. Obviously, this kind of irregular sharp angle cannot be avoided in natural corrosion or artificial accelerated corrosion tests, so the random pits generated based on CA technology proposed in this paper are more in line with reality.

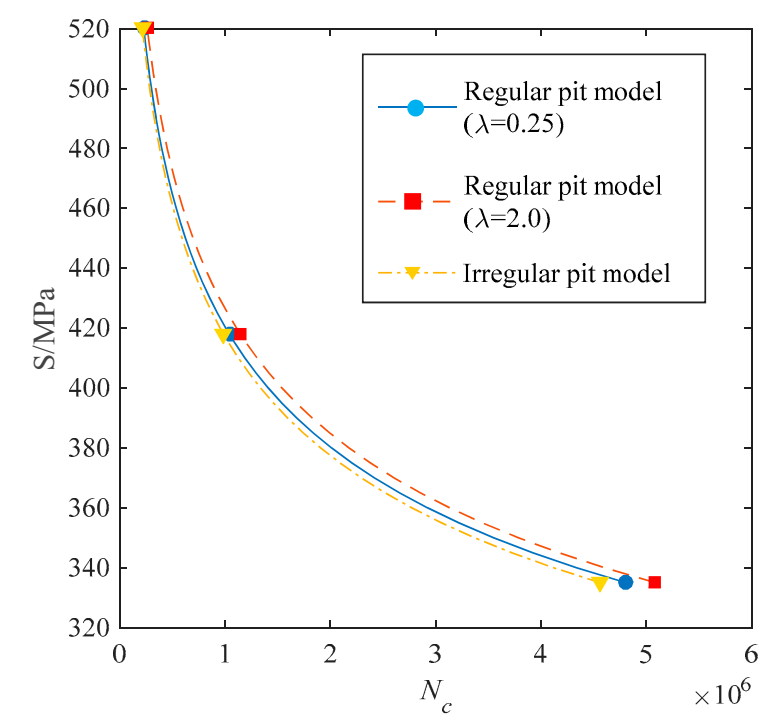

Figure 14. S-N curves of pre-corroded steel wire with mass loss rate of $0.25 \%$.
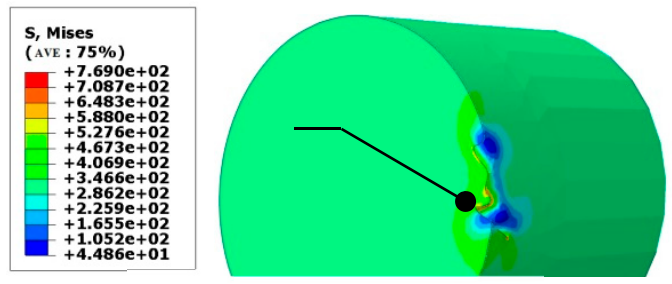

(a)

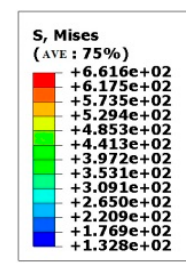

$+1.328 \mathrm{er}+02$

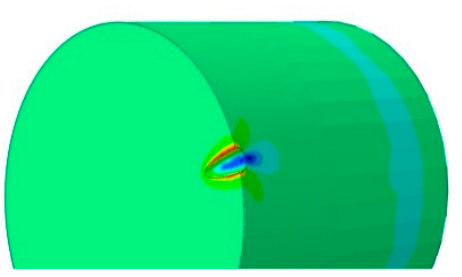

(b)

Figure 15. Stress contours of random pit model and two semi-ellipsoidal pit models with mass loss rate of $0.25 \%$. (a) Random corrosion pit; (b) Hemi-ellipsoidal corrosion pit $(\lambda=0.25)$.

Figure 16 is the time-varying curves of the stress intensity factor of steel wires with different pit morphologies. From the point of view of damage accumulation, the initial damage of the regular pit model with a shape factor of 0.25 is the greatest, but the random pit model has the fastest damage accumulation rate, which leads to it being that at the 40th step, the damage degree in the latter is greater than that in the former. In addition, the initial damage of regular pit model with a shape factor of 0.25 is almost three times that of regular pit model with a shape factor of 2.0, indicating that the initial pit depth (corresponding to the initial damage degree) is the main reason for the difference in fatigue life between regular pit models. 


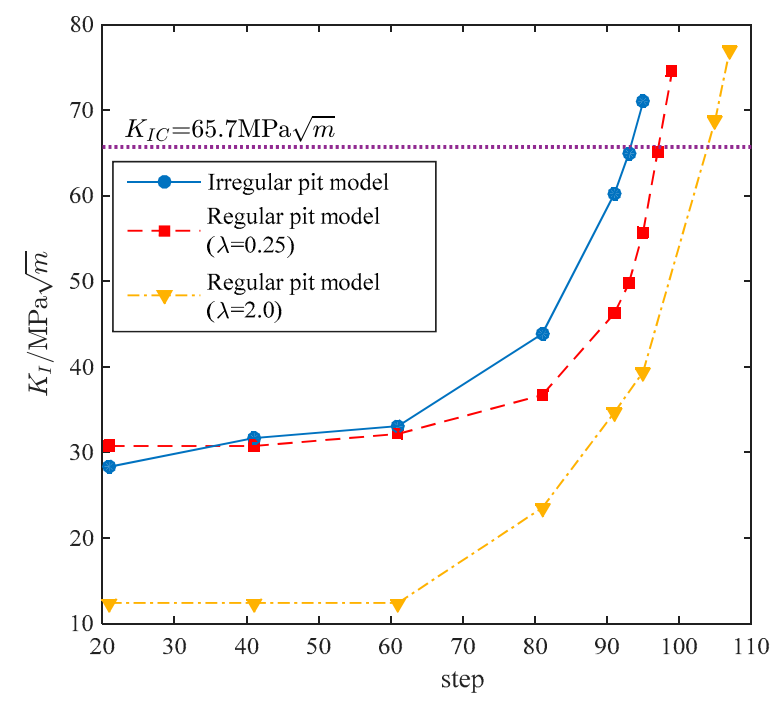

Figure 16. Time-varying curves of the stress intensity factor for steel wire with different pit morphologies.

The hemi-ellipsoidal pit models with a mass rate of $2.5 \%$ are established, which is consistent with the mass loss rate of the random pit model generated by CA technology in Figure 8c. The simulative results are shown in Table 3. By comparing Table 2 with Table 3, in the steel wire model, the increasing rate of fatigue life at a mass loss rate of $2.5 \%$ is significantly higher than that at a mass loss rate of $0.25 \%$.

Table 3. Fatigue life of pre-corroded steel wire with a regular corrosion pit ( $\eta=2.5 \%$ ).

\begin{tabular}{ccccc}
\hline S/MPa & $n$ & $\lambda$ & $x / \mathbf{m m}$ & $\boldsymbol{N}_{\boldsymbol{c}}$ \\
\hline \multirow{4}{*}{335} & \multirow{2}{*}{20,000} & 0.25 & 1.9443 & $2,100,000$ \\
& & 0.5 & 1.2248 & $3,180,000$ \\
& & 1.5 & 0.7716 & $3,560,000$ \\
& 2.0 & 0.589 & $3,640,000$ \\
418 & \multirow{3}{*}{10,000} & 0.486 & $3,720,000$ \\
& & 0.5 & 1.9443 & - \\
& & 1.0 & 0.7716 & 730,000 \\
& & 2.0 & 0.589 & 790,000 \\
520 & \multirow{3}{*}{1000} & 0.25 & 1.9443 & 800,000 \\
& & 0.5 & 1.2248 & - \\
& & 1.0 & 0.7716 & 141,000 \\
& & 2.0 & 0.589 & 158,000 \\
& & 0.486 & 168,000 \\
\hline
\end{tabular}

Note: The stress intensity factor $K_{I}$ for steel wire crack has reached the critical value $K_{I C}$ under the cyclic stress with stress range of $418 \mathrm{MPa}$ or $520 \mathrm{MPa}$ when $\lambda$ is 0.25 . Failure of the steel wire will occur, so the fatigue life in this case is not discussed.

Figure 17 shows the S-N curves of the pre-corroded steel wires with a hemi-ellipsoidal pit and they are compared with that of steel wire with a random corrosion pit. When the mass loss rate is $2.5 \%$, the fatigue life of random pit model is less than that of regular pit models, even if the maximum depth of the random pit model is less than that of regular pit model with a shape factor of 0.5 .

Figure 18a,b are the stress contours of the random pit and hemi-ellipsoidal pit model with shape factors of 0.5 . In contrast to the model with a mass loss rate of $0.25 \%$, the random pit model with a mass loss rate of $2.5 \%$ has more irregular shape angles, which lead to a larger stress in the random pit model and a larger gap with the regular pit model. 


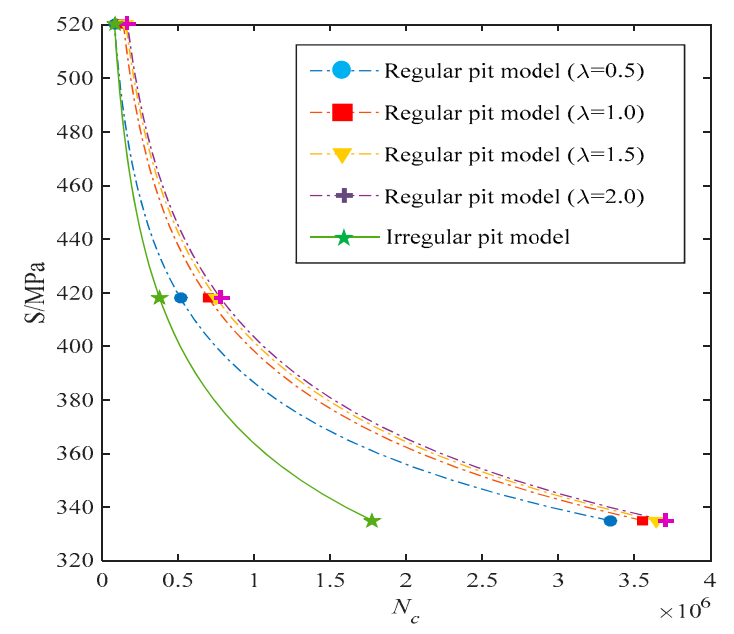

Figure 17. S-N curves of pre-corroded steel wire with mass loss rate of $2.5 \%$.

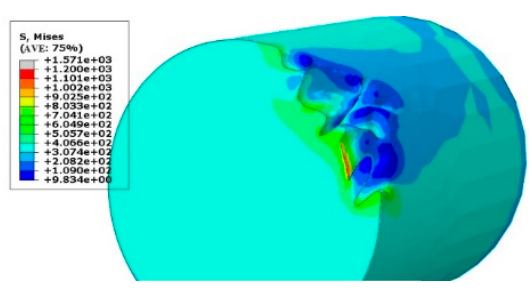

(a)

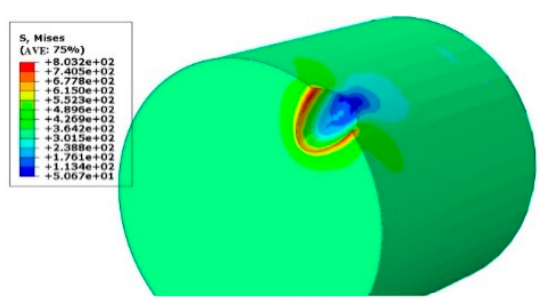

(b)

Figure 18. Stress contours of random pit model and two hemi-ellipsoidal pit models with mass loss rate of $2.5 \%$. (a) Random corrosion pit; (b) Hemi-ellipsoidal corrosion pit $(\lambda=0.5)$.

Figure 19 represents the time-varying curves of the stress intensity factor for steel wire with different pit morphologies. From Figure 19, it can be seen that the difference between regular and irregular corrosion pit models is larger than that in models with a mass loss rate of $0.25 \%$, as shown in Figure 16. In conclusion, the difference in fatigue life between regular pit models and irregular pit models increases with the increase in mass loss rate.

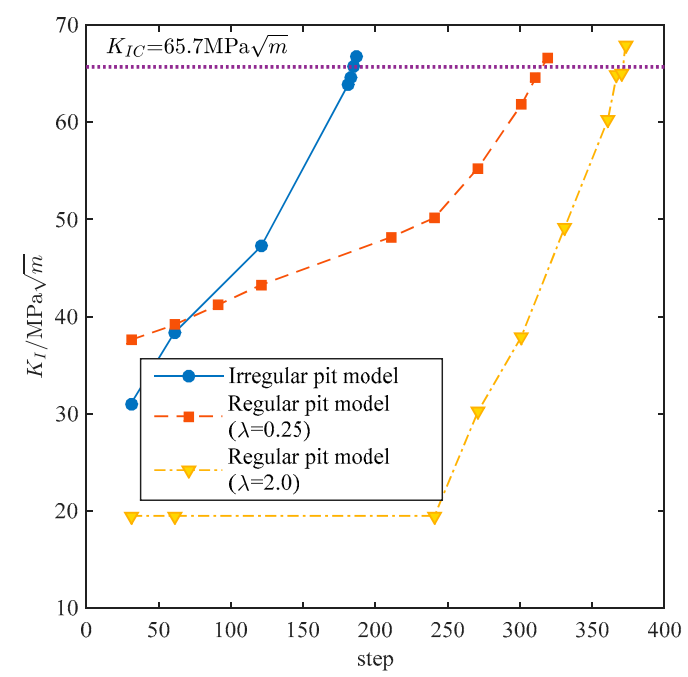

Figure 19. Time-varying curves of the stress intensity factor for steel wire with different pit morphologies. 


\section{Conclusions}

A new numerical simulation method was proposed in this paper to study the damage evolution and failure process of high-strength steel wires with a pre-corrosion defect in cable-stayed bridges under fatigue loads. By using the proposed simulative method, the S-N curves of the steel wires with different corrosion degrees were obtained and damage evolution of corroded steel wires was investigated. The results show that the influence of pitting corrosion on fatigue life is much greater than that of the mass loss caused by corrosion; stress concentration occurs in the middle of the corrosion pit, where damage began to accumulate; as the load continues to apply, damage accumulates and penetrates into the inner part of the steel wire far from the pit, and the rate of damage evolution gradually increases.

In addition, the influence of initial pitting morphology on fatigue life was presented by comparing the irregular pit model with the regular pit models. It was found that the fatigue life of the pre-corroded steel wire increases gradually with an increase in the pit shape factor, that is, a reduction in the pit depth. In addition, compared with wide-shallow pits, narrow and deep pits have a greater impact on the fatigue performance of steel wires.

By comparing the regular pit models with irregular pit models developed by the proposed method, it was found that the irregular shape angle is the main reason for the smaller fatigue life and the larger stress concentration in the irregular pit model than in the regular pit model. With the increase in the mass loss rate, the influence of the irregular shape angle is more obvious and the difference in fatigue life between the irregular pit model and regular pit model increases.

Author Contributions: Conceptualization, Y.W.; methodology, Y.Z.; writing-original draft preparation, Y.Z.; writing-review and editing, Y.Z.; supervision, Y.W.; project administration, Y.W.; funding acquisition, Y.W.

Funding: This research was funded by the National Natural Science Foundation of China, grant number 51678135; the Natural Science Foundation of Jiangsu Province, grant number BK20171350; the Fundamental Research Funds for the Central Universities, grant number 2242016R30009; the Priority Academic Program Development of Jiangsu Higher Education Institutions (PAPD), the Top-notch Academic Program Project of Jiangsu Higher Education Institutions (TAPP); Six Talent Peak Projects in Jiangsu Province, grant number JNHB-007.

Conflicts of Interest: The authors declare no potential conflicts of interest.

\section{References}

1. Watson, S.C.; Stafford, D. Cables in trouble. Civ. Eng. ASCE 1988, 58, 38-41.

2. Dawson, D.B.; Pelloux, R.M. Corrosion fatigue crack growth of titanium alloys in aqueous environments. Metall. Trans. 1974, 5, 723-731. [CrossRef]

3. Müller, M. Theoretical Considerations on Corrosion Fatigue Crack Initiation. Metall. Trans. A 1982, 13, 649-655. [CrossRef]

4. Hirose, Y.; Mura, T. Crack nucleation and propagation of corrosion fatigue in high-strength steel. Eng. Fract. Mech. 1985, 22, 859-870. [CrossRef]

5. Kim, S.; Kang, Y.J. Structural behavior of cable-stayed bridges after cable failure. Struct. Eng. Mech. 2016, 59, 1095-1120. [CrossRef]

6. Mahmoud, K.M. Fracture strength for a high strength steel bridge cable wire with a surface crack. Theor. Appl. Fract. Mech. 2007, 48, 152-160. [CrossRef]

7. Zheng, X.L.; Xie, X.; Li, X.Z.; Hu, J.M.; Sun, W.Z. Fatigue fracture surface analysis and fatigue life estimation of corroded steel wires. China J. Highw. Transp. 2017, 30, 79-86. (In Chinese)

8. Sankaran, K.K.; Perez, R.; Jata, K.V. Effects of pitting corrosion on the fatigue behavior of aluminum alloy 7075-T6: Modeling and experimental studies. Mater. Sci. Eng. A (Struct. Mater. Prop. Microstruct. Process.) 2001, 297, 223-229. [CrossRef]

9. Nakamura, S.I.; Suzumura, K. Hydrogen embrittlement and corrosion fatigue of corroded bridge wires. J. Constr. Steel Res. 2009, 65, 269-277. [CrossRef]

10. Nakamura, S.; Suzumura, K. Experimental Study on Fatigue Strength of Corroded Bridge Wires. J. Bridge Eng. 2013, 18, 200-209. [CrossRef] 
11. Zheng, X.; Xie, X.; Li, X. Experimental Study and Residual Performance Evaluation of Corroded High-Tensile Steel Wires. J. Bridge Eng. 2017, 22, 04017091. [CrossRef]

12. Chao, J.; Chong, W.; Xu, J. Experimental study on fatigue performance of corroded high-strength steel wires used in bridges. Constr. Build. Mater. 2018, 187, 681-690.

13. Ye, H.W.; Huang, Y.; Wang, Y.Q.; Qiang, S.Z. Fatigue life estimation of corroded bridge wires based on theory of critical distances. J. Southwest Jiatong Univ. 2015, 50, 294-299. (In Chinese)

14. Turnbull, A.; Wright, L.; Crocker, L. New insight into the pit-to-crack transition from finite element analysis of the stress and strain distribution around a corrosion pit. Corros. Sci. 2010, 52, 1492-1498. [CrossRef]

15. Li, C.X.; Tang, X.S.; Xiang, G.B. Fatigue crack growth of cable steel wires in a suspension bridge: Multiscaling and mesoscopic fracture mechanics. Theor. Appl. Fract. Mech. 2010, 53, 113-126. [CrossRef]

16. Sun, B. A continuum model for damage evolution simulation of the high strength bridge wires due to corrosion fatigue. J. Constr. Steel Res. 2018, 146, 76-83. [CrossRef]

17. Hu, P.; Meng, Q.; Hu, W.; Shen, F.; Zhan, Z.; Sun, L. A continuum damage mechanics approach coupled with an improved pit evolution model for the corrosion fatigue of aluminum alloy. Corros. Sci. 2016, 113, 78-90. [CrossRef]

18. GB/T18590-2001, Corrosion of Metals and Alloys-Evaluation of Pitting Corrosion; Standards Press of China: Beijing, China, 2001.

19. Kachanov, L.M. Time rupture process under creep conditions. Izv. Akad. Nauk. Ssr 1958, 8, $26-31$.

20. Chowdhury, D.; Santen, L.; Schadschneider, A. Statistical physics of vehicular traffic and some related systems. Phys. Rep. 2000, 329, 199-329. [CrossRef]

21. Wimpenny JW, T.; Colasanti, R. A unifying hypothesis for the structure of microbial biofilms based on cellular automaton models. Fems Microbiol. Ecol. 1997, 22, 1-16. [CrossRef]

22. Ding, R.; Guo, Z.X. Microstructural modelling of dynamic recrystallisation using an extended cellular automaton approach. Comput. Mater. Sci. 2002, 23, 209-218. [CrossRef]

23. di Caprio, D.; Vautrin-Ul, C.; Stafiej, J.; Saunier, J.; Chaussé, A.; Féron, D.; Badiali, J.P. Morphology of corroded surfaces: Contribution of cellular automaton modelling. Corros. Sci. 2011, 53, 418-425. [CrossRef]

24. Caprio, D.D.; Vautrinul, C.; Stafiej, J.; Chausse, A.; Feron, D.; Badiali, P.J. Cellular automata approach for morphological evolution of localised corrosion. Br. Corros. J. 2013, 46, 223-227. [CrossRef]

25. Stafiej, J.; Caprio, D.D.; Bartosik, U. Corrosion-passivation processes in a cellular automata based simulation study. J. Supercomput. 2013, 65, 697-709. [CrossRef]

26. Leifer, J.; Mickalonis, J.I. Prediction of aluminum pitting in natural waters via artificial neural network analysis. Corrosion 2000, 56, 563-571. [CrossRef]

27. Rajasankar, J.; Iyer, N.R. A probability-based model for growth of corrosion pits in aluminum alloys. Eng. Fract. Mech. 2006, 73, 553-570. [CrossRef]

28. Rokhlin, S.I.; Kim, J.Y.; Nagy, H.; Zoofan, B. Effect of pitting corrosion on fatigue crack initiation and fatigue life. Eng. Fract. Mech. 1999, 62, 425-444. [CrossRef]

29. Valor, A.; Caleyo, F.; Alfonso, L.; Rivas, D.; Hallen, J.M. Stochastic modeling of pitting corrosion: A new model for initiation and growth of multiple corrosion pits. Corros. Sci. 2007, 49, 559-579. [CrossRef]

30. Wang, H.; Lu, G.; Wang, L.; Zhang, Y. Cellular automaton simulation of surface corrosion damage evolution. Acta Aeronaut. ET Astronaut. Sin. 2008, 30, 1490-1496. (In Chinese)

31. Pidaparti, R.M.; Palakal, M.J.; Fang, L. Cellular Automation Approach to Model Aircraft Corrosion Pit Damage Growth. AIAA J. 2004, 42, 2562-2569. [CrossRef]

32. Pidaparti, R.M.; Fang, L.; Palakal, M.J. Computational simulation of multi-pit corrosion process in materials. Comput. Mater. Sci. 2008, 41, 255-265. [CrossRef]

33. Vautrin-Ul, C.; Taleb, A.; Stafiej, J.; Chausse, A.; Badiali, J.P. Mesoscopic modelling of corrosion phenomena: Coupling between electrochemical and mechanical processes, analysis of the deviation from the Faraday law. Electrochim. Acta 2007, 52, 5368-5376. [CrossRef]

34. Lan, C.; Xu, Y.; Ren, D.L.; Li, N.; Liu, Z. Fatigue property assessment of parallel wire stay cable I: Fatigue life model for wire. China Civ. Eng. J. 2017, 50, 66-74.

35. Zheng, X.L.; Xie, X.; Li, X.Z.; Tang, Z.Z. Fatigue crack propagation characteristics of high-tensile steel wires for bridge cables. Fatigue Fract. Eng. Mater. Struct. 2019, 42, 256-266. [CrossRef]

36. Lan, C.; Xu, Y.; Liu, C.; Li, L.; Spencer, B.F., Jr. Fatigue life prediction for parallel-wire stay cables considering corrosion effects. Int. J. Fatigue 2018, 114, 81-91. [CrossRef] 
37. Wang, Y.; Zheng, Y.Q. Simulation of Damage Evolution and Study of Multi-fatigue Source Fracture of Steel Wire in Bridge Cables Under the Action of Pre-corrosion and Fatigue. CMES Comput. Model. Eng. Sci. 2019. [CrossRef]

38. Pan, X.Y.; Xie, X.; Li, X.Z.; Sun, W.; Zhu, H.H. Mechanical properties and grading method of corroded high-tensile steel wires. J. Zhejiang Univ. (Eng. Sci.) 2014, 48, 1917-1924.

39. GB/T 17101-2008, Hot-Dip Galvanized Wires for Bridge Cables; China Standard press: Beijing, China, 2008. (In Chinese)

40. Harlow, D.G.; Wei, R.P. Probabilities of occurrence and detection of damage in airframe materials. Fatigue Fract. Eng. Mater. Struct. 2010, 22, 427-436. [CrossRef]

41. Muhammet, C. Corrosion pit-induced stress concentration in spherical pressure vessel. Thin Walled Struct. $2019,136,106-112$.

(C) 2019 by the authors. Licensee MDPI, Basel, Switzerland. This article is an open access article distributed under the terms and conditions of the Creative Commons Attribution (CC BY) license (http://creativecommons.org/licenses/by/4.0/). 